\title{
Farnesyl Pyrophosphate Synthetase
}

National Cancer Institute

\section{Source}

National Cancer Institute. Farnesyl Pyrophosphate Synthetase. NCI Thesaurus. Code C118212.

Farnesyl pyrophosphate synthase (419 aa, $\sim 48 \mathrm{kDa}$ ) is encoded by the human FDPS gene. This protein plays a role in the synthesis of geranyl pyrophosphate and farnesyl pyrophosphate. 